\title{
Narrativas de remoção: A diáspora NEGRA ENTRE MEMÓRIAS, DESLOCAMENTOS E RESISTÊNCIAS
}

\author{
JÚLIA Almeida \\ Universidade Federal do Espírito Santo
}

\section{Resumo}

A partir de leitura comparatista e interdisciplinar, são cotejados os romances Becos da memória, da escritora brasileira Conceição Evaristo (2013), e Texaco, do escritor martinicano Patrick Chamoiseau (1992), como narrativas de processos de remoção urbana que reconstituem as memórias e as experiências da territorialização precária da diáspora negra nas Américas.

\section{Abstract}

Based on a comparative and interdisciplinary perspective, we analyze Becos da memória, by the Brazilian writer Conceição Evaristo, and Texaco, by the Martinican writer Patrick Chamoiseau, as narratives of urban removal processes rewriting the memories and the experiences of precarious territorialization of the black diaspora in the Americas.

\section{Palavras-chave}

Literatura comparada, Diáspora negra, Remoção urbana, Literatura e afrodescendência, Américas,

Memória.

\section{Keywords}

Comparative literature

Black diaspora

Urban removal,

Literature and

Afrodescendency

Americas,

Memory. 
As milhares de remoções em curso no cenário dos megaeventos no Brasil colocam em pauta a luta de populações periferizadas pelo território e pela moradia e reatualizam o interesse de pesquisadores pelo tema do deslocamento urbano forçado, que não é prerrogativa dos brasileiros, como afirma Rogério Haesbaert: "a exclusão aviltante ou as inclusões extremamente precárias a que as relações capitalistas relegaram a maior parte da humanidade faz como que muitos, no lugar de partilharem múltiplos territórios, vaguem em busca de um, o mais elementar território da sobrevivência cotidiana". ${ }^{1}$ É a esse processo de vagância em busca de um território que o autor reserva uma concepção mais social de desterritorialização, que pensa a territorialização (material e imaginária) sob condições de exclusão socioespacial, invertendo as interpretações hegemônicas que expressam sempre positivamente os processos contemporâneos de deslocalização e de mobilidade. ${ }^{2}$

Nossa investida nos romances Becos da memória, de Conceição Evaristo (2013), e Texaco, de Patrick Chamoiseau (1992), pretende, assim, acercar-se de práticas literárias que tratam de processos de remoção urbana no Brasil e Martinica, em busca de indagar uma possível estrutura de sentimento, ${ }^{3}$ isto é, características comuns a escritores que formularam respostas a determinadas condições subjacentes e formativas da precária territorialização da diáspora negra nas Américas, constituindo, como sugere Williams, "a dramatização de um processo, a criação de uma ficção em que os elementos constitutivos reais da vida social e das crenças foram simultaneamente atualizados e, de forma importante, vividos de modo diverso, a diferença residindo no ato criativo". 4

O texto se divide em três partes: na primeira, tratamos dos conceitos operatórios de diáspora, lugar de enunciação e prática literária, com os quais formularemos um olhar sobre essas escritas diaspóricas; na segunda, faremos a apresentação e cotejo dos romances, indagando o modo como tomam narrativas orais na produção de uma memória da escravidão e de uma figuração do enraizamento/desenraizamento; por fim, retomaremos a pergunta sobre uma estrutura de sentimento comum a essas práticas de escrita na diáspora negra.

\section{Pressupostos: lugares de fala / escrita desde a diáspora negra}

Desde que os textos do círculo de Bakhtin e os estudos de E. Benveniste inseriram a enunciação, o discurso e a intersubjetividade no centro dos estudos linguísticos e literários, conceituações diversificadas de lugar/posição de fala/enunciação passaram a alimentar boa parte das reflexões contemporâneas sobre a linguagem, a cultura e o conhecimento. Mais recentemente, os estudos culturais têm se valido sobremaneira das implicações dessas teorias da enunciação e da ideia de que falamos e escrevemos desde um lugar, um tempo, uma história e uma cultura específicas que posicionam e localizam os discursos e os sujeitos $d a$ cultura, seja na literatura, no cinema e na produção cultural em geral. ${ }^{5}$

Se as noções geográficas de espaço, lugar, local, posição têm servido para a explicitação das condições do discurso, fazem-no de forma simbólica, já que os espaços de fala, longe de coincidirem apenas com coordenadas geográficas e materiais dadas, são espaços vividos, sentidos, imaginados, negociados, sobretudo conquistados e inventados. É, nesse sentido, que Hall trata do novo cinema caribenho "não como um pobre espelho erguido para refletir o que existe, mas sim como uma forma de representação que

\footnotetext{
${ }^{1}$ HAESBAERT, Rogério. O mito da desterritorialização. Rio de Janeiro: Bertrand Brasil, 2014, p.17.

${ }^{2}$ Ibidem.

${ }^{3}$ WILLIAMS, Raymond. Cultura e materialismo. São Paulo: Editora Unesp, 2011.

${ }^{4}$ Ibidem, p.34-35.

${ }^{5}$ HALL, Stuart. "Identidade Cultural e Diáspora". Revista do Patrimônio Histórico e Artístico Nacional, n. 24, Rio de Janeiro, Instituto do Patrimônio Histórico e Artístico Nacional, p. 68-75, 1996.
} 
é capaz de nos constituir como sujeitos e temas de novos tipos, permitindo-nos, por conseguinte, descobrir lugares desde os quais falamos"; o que implica uma "política da posição" nessas estéticas, atravessadas pelo diálogo tenso entre o modo como o sujeito negro foi historicamente posicionado ou situado pelas representações coloniais e eurocêntricas e o modo como constroi novos posicionamentos ou posicionalidades, os "pontos instáveis de identificação ou sutura, feitos no interior do discurso, da cultura e da história". ${ }^{7}$

Ainda com Hall, ${ }^{8}$ vislumbramos uma concepção metafórica e não retrógada de diáspora, que permite corrigir aquela usada tradicionalmente em relação a Israel, formulada em termos de volta à terra sagrada e de expulsão dos demais. Ao contrário, a concepção de diáspora do autor reconhece a diversidade e a heterogeneidade necessárias, expressando o modo de vida de zonas de contato e uma etnicidade não imperializante. Segundo o autor, as experiências negras resultantes da história comum das diásporas forçadas no Caribe - e que poderíamos estender às Américas em geral - são atravessadas pela diferença e pelo modo como povos e países foram negociando as relações entre: uma presença/ausência africana ao mesmo tempo reprimida, resistente e redescoberta; uma presença dominante europeia que institui a diferença colonial, mas é também sincretizada, contagiada; e a presença do Novo Mundo, a do território e dos numerosos deslocamentos dos povos indígenas, colonizadores, escravos, imigrantes, o lugar por excelência das diásporas e de suas narrativas.

Se aceitarmos o paradigma metodológico que nos propõe Raymond Williams ${ }^{9}$ para a análise de obras artístico-literárias, quando afirma que "não devemos olhar para os componentes de um produto [ou objeto], mas sim para as condições de uma prática" e para as práticas relacionadas sob mesmas condições, podemos entender melhor nosso esforço em direção a essas narrativas de remoção urbana na diáspora transatlântica. Relacionar práticas de escrita que, de uma perspectiva afrodescendente, tomam a fragilidade territorial da população negra como matéria de expressão é também buscar um modo coletivo - transnacional, transatlântico, diaspórico - de dizer as experiências da fixação/ deslocamento dessas populações, a que os valores e significados hegemônicos em nossos países reservam uma mínima representação.

Essas escritas constituem, assim, espaços de fala conquistados no bojo de populações a quem se limita o acesso aos direitos, à educação e à escrita, às condições de vida e ao território de existência. Conceição Evaristo e Patrick Chamoiseau são ambos oriundos de bairros populares, nascidos na metade do século XX, e com seus romances, Becos da memória e Texaco, respectivamente, introduzem na literatura contemporânea do final do século XX perspectivas internas e muito próximas da vida socioespacial da população afrodescendente nos últimos 150 anos, que nos permitem vislumbrar a condição de uma prática literária que coloca em presença as heranças da escravidão nas Américas, assim como propunha Édouard Glissant, em Mémoires des esclavages: "trata-se de operar um movimento contrário àquele que se passa nas histórias dessas escravidões, da América do Norte, do Caribe, do Brasil, do Oceano Índico: elas permaneceram opacas e indistintas e se tornaram impermeáveis umas às outras". ${ }^{10}$ Reinserir essas escritas no contexto da diáspora africana nas Américas permite, assim, analisar práticas e significados de forma não isolada, religando as questões locais e tornando-as permeáveis e passíveis de uma compreensão dilatada em sua complexa inserção transnacional.

\footnotetext{
${ }^{6}$ Ibidem, p.75.

${ }^{7}$ Ibidem, p.70.

${ }^{8}$ HALL, Stuart. Da diáspora. Belo Horizonte: Ed. da UFMG, 2003.

${ }^{9}$ WILLIAMS, op. cit., p.66.

${ }^{10}$ GLISSANT, Édouard. Mémoires des esclavages. Paris: Gallimard, 2007, p.147.
} 


\section{Entre Becos e Texaco}

Becos da memória é um romance que narra o processo de remoção em uma favela brasileira, remetendo às experiências de Conceição Evaristo como moradora do Morro do Pindura Saia, em Belo Horizonte, cuja ambiência a escritora afirma ter registrado numa espécie de crônica escolar em 1968: "a ambiência de uma favela que não existe mais". ${ }^{11}$ Escrito a partir de 1987, o livro tem sua primeira edição em 2006, pela Editora Mazza, enfrentando nesse intervalo toda a dificuldade de publicação que tem em geral a literatura afro-brasileira. Evaristo afirma ser Becos da memória o seu "primeiro experimento em construir um texto ficcional con(fundindo) escrita e vida". ${ }^{12}$ É conhecido o seu conceito que sustenta esta prática, escrevivência, desenvolvido em trabalhos acadêmicos que produz como pesquisadora sensível às questões da cultura e da escrita negras. Entre a escrita de Becos da memória e sua publicação em 2006, veio a público o romance Ponciá Vicêncio, também pela Mazza, em 2003, seguidos ambos pelas publicações de contos, poemas e ensaios e de uma reedição de Becos em 2013, pela Ed. Mulheres. A escritora nasceu em 1946, em Belo Horizonte, e integra, junto com Joel Rufino dos Santos, Muniz Sodré, Nei Lopes, entre outros, o que segundo Eduardo de Assis Duarte ${ }^{13}$ seria a geração de consolidação da literatura afro-brasileira, que nascida nas décadas de 30 e 40, beneficiou-se do "fortalecimento de uma consciência afrodescendente no país", vindo a publicar a partir da segunda metade do século XX.

Texaco, de Patrick Chamoiseau, foi publicado em 1992 na França, pela Gallimard, dando para o escritor o prêmio Goncourt e sendo considerado uma obra-prima escrita entre o francês e o crioulo, em um francês "crioulizado". Narra a tentativa de demolição do bairro popular Texaco, em Fort-de-France, entre 1980 e 1983, a partir de um processo de escrita em que o espírito etnográfico e histórico está a serviço da reescrita da história da escravidão na Martinica e suas heranças. Nascido em 1953, em um bairro popular de Fort-de-France, Chamoiseau publicou uma obra extensa de contos, romances, ensaios e manifestos, em que a creolité foi objeto de uma construção estética e teórica, juntamente com outros autores caribenhos, como Édouard Glissant, Raphaël Confiant e Jean-Luc de Laguarigue. Antes de Texaco, publicou Chronique des sept miseres, em 1986, e Antan d'enfance, em 1990, que deu origem à trilogia em que evoca sua infância, juntamente com Chémin d'école e À bout d'enfance, publicados em 1994 e 2005, respectivamente.

Dois escritores e duas obras marcados por um lugar de fala afro-identificado, que reinscrevem no nosso presente memórias da escravidão, do êxodo e da deambulação dos descendentes de escravos e o resultado mais visível desses processos históricos e sociais nas cidades contemporâneas. Becos da memória aguça ainda uma perspectiva "feminina e afrodescendente" ao narrar "as agruras de uma população favelada em vias de remoção", ${ }^{14}$ assim como Carolina Maria de Jesus narra, no conto "Favela", ${ }^{15}$ os processos de despejo na São Paulo de 1948 e sua deambulação entre "mulheres com filhos e sem lar", inscrevendo nas letras o cotidiano da mulher e mãe favelada e os tortuosos caminhos da sobrevivência. Em Texaco, a condição masculina da autoria é sensível à inscrição de uma voz feminina, a líder comunitária MarieSophie Laborieux, que protagoniza a luta pelo bairro popular Texaco ao narrar a saga de três gerações de sua família.

\footnotetext{
${ }^{11}$ EVARISTO, Conceição. Becos da Memória. Florianópolis: Ed. Mulheres, 2013, p.13.

${ }^{12}$ Ibidem, p. 11 .

${ }^{13}$ DUARTE, Eduardo de Assis. Entre Orfeu e Exu, a afrodescendência toma a palavra. In: Duarte, Eduardo de Assis (Org.) Literatura e Afrodescendência no Brasil: Antologia Crítica - Precursores. Belo Horizonte: Editora UFMG, 2011, p.37.

${ }^{14}$ CAMPOS, Maria Consuelo Cunha; DUARTE, Eduardo de Assis. Conceição Evaristo. In: DUARTE, Eduardo de Assis (Org.) Literatura e Afrodescendência no Brasil: Antologia crítica - Consolidação. Belo Horizonte: Editora UFMG, 2011, p.211.

${ }^{15}$ JESUS, Carolina Maria de. "Favelas". In: JESUS, Carolina Maria de. Onde estaes felicidade? São Paulo: Me Parió Revolução, 2014, p.41.
} 
Acreditamos que um cotejo dos dois romances pode ser feito observando como a experiência do desenraizamento e da territorialização precária, incrustada nas histórias contadas e recontadas pelos personagens e na produção de significados da terra e o território, do campo e da cidade, permite que se reinvente uma memória coletiva, materializada idealmente na escrita, que prefigura o lugar (necessário) do escritor nessas comunidades. Esses livros autorrepresentam a própria condição da escrita afrodescendente, capaz de devolver o olhar e rever as concepções hegemônicas da deslocalização e sua crítica à semântica do enraizamento.

Tanto Becos da memória quanto Texaco narram processos de remoção no contexto da segunda metade do século XX em grandes cidades da América Latina e Caribe. Não obstante sua fixação temporal e espacial numa atualidade que reconhecemos como próxima de nosso presente, essas narrativas tratam das remoções de uma perspectiva radicalmente distinta daquela com que nos habituamos a ver os sujeitos removidos nas mídias e reportagens. Aqui a fala interna ao processo de remoção permite que essas narrativas constituam uma relação muito particular com o espaço narrado, em que o território é percebido de dentro e na duração própria à cadência dos fatos (da remoção) que modificam a relação desses sujeitos com o espaço e com a própria comunidade. Esse lugar do sujeito em remoção, em especial das protagonistas dos romances, a menina Maria-Nova, de Becos da memória, e a líder comunitária Marie-Sophie Laborieux, de Texaco, é também o lugar de inscrição e resgate de uma memória oral de relatos que vêm, desde os antepassados que viveram a escravidão, dar sentido aos fatos do cotidiano. Vejamos mais detalhadamente cada caso.

\subsection{Becos da Memória: o território como escuta}

Em Becos da memória, Maria-Nova é justamente quem "coleciona na cabeça e no fundo do coração" histórias ou "pedras pontiagudas", ${ }^{16}$ que abrem o romance para histórias de escravidão, ouvidas de Tio Totó e de sua terceira mulher Maria-Velha, histórias de fazenda e luta que lhe conta Bondade, histórias de guerra de Tio Tatão, entre muitas outras. Essas histórias da escravidão, de conflitos por terra, de deslocamentos forçados se reescrevem no cotidiano da favela, nutrindo o desejo da protagonista de recontá-las: "um dia, não se sabia como, ela haveria de contar tudo aquilo ali". ${ }^{17}$

No romance, as referências à terra, ao território e à cidade constituem uma via de acesso pela linguagem ao processo de desenraizamento constante da população negra, sobretudo pelas narrativas de Tio Totó que, nascido após a Lei do Ventre Livre, encarna uma trajetória de vida marcada pela perda reiterada da terra, do território e, consequentemente, de vidas:

Quem disse que o homem não gostaria de ter raízes que o prendessem à terra? ${ }^{18}$

Perdi um lugar, uma terra, que pais de meus pais diziam que era um lugar grande, de mato, bichos. De gente livre e sol forte... E hoje, agora a gente perde um lugar de que eu já pensava dono. Perder a favela! Bom que meu corpo já está pedindo terra. ${ }^{19}$

Cova, lugar de minha derradeira mudança. ${ }^{20}$

Suas narrativas de deslocamento desde a venda das fazendas coloniais e o impulso de "esquecer as histórias de escravidão, suas e de seus pais" ${ }^{21}$ são testemunho da busca de localização, em que a favela representa moradia e subsistência, com um "pedacinho de terra que havia em volta do barraco, [onde] plantavam mandioca, milho e verduras". ${ }^{22}$

\footnotetext{
${ }^{16}$ EVARISTO, op.cit., p.49 e 47, respectivamente.

${ }^{17}$ Ibidem, p.49.

18 Ibidem, p.31.

${ }^{19}$ Ibidem, p.45.

${ }^{20}$ Ibidem, p.36.

${ }^{21}$ Ibidem, p.34.

${ }^{22}$ Ibidem, p. 224.
} 
É essa "vida plantada" 23 e "espremida" que a remoção coloca em risco, mostrando como o sentido de território pode ser frágil quando aplicado às favelas brasileiras, já que não há uma "uma zona razoavelmente bem delimitada e sob controle dos grupos que aí se reproduzem", ${ }^{24}$ sendo cruciais os laços sociais e com o espaço vivido (territorialização simbólica), o que compensa as condições funcionais muito precárias.

Com o processo de remoção em curso, percebe-se melhor a desterritorialização aqui entendida como “exclusão, privação e/ou precarização do território enquanto 'recurso' ou 'apropriação' (material e simbólica) indispensável à nossa participação efetiva como membros de uma sociedade"25: "o território nosso já se resumia ao quase nada". ${ }^{26}$

E esse processo de "desfavelamento" é narrado em todas as suas fases e nas sucessivas violações que impõe aos direitos dessas populações. Sem informação em tempo hábil, os homens "exigiam a saída rapidamente dos moradores. Que se juntassem logo os trapos!". ${ }^{27} \mathrm{O}$ romance registra também o quanto a desinformação é parte do processo: "o plano de desfavelamento também aborrecia e confundia a todos [...] Dava a impressão de que nem eles sabiam direito porque estavam erradicando a favela". ${ }^{28}$ Ameaças, pressão política e psicológica, retirada dos serviços públicos e, finalmente, a remoção violenta completam a sequência de ações que levam ao desfecho de Becos da memória: "mais duas ou três torneiras foram retiradas. Era preciso pressionar e encurralar o pessoal", ${ }^{29}$ até o momento em que "as mudanças, trouxas, latas, meninos e grandes, cachorros, desamparo, merda e merda, tudo era acomodado desacomodadamente no caminhão"30 ou, na falta disso, "houve pessoas que assumiram a mendicância e foram morar na rua". ${ }^{31}$

É Negro Alírio, no romance, "o único que pisava num solo que sabia ser seu", ${ }^{32}$ pois aprendera não só a "ler cada palmo da terra, cada pé de cana, cada semente de milho", como lia a realidade, "o que estava e o que não estava escrito" e "cada rosto de um irmão seu". ${ }^{33}$ A territorialização comunitária que constrói ao seu redor faz frente ao sofrimento isolado de cada um, de cada família impactada pelo processo do desfavelamento. O "solo" em que Negro Alírio planta sua vida é o da leitura, da compreensão do mundo, da libertação, da luta, da construção da vida. "Direitos sonegados" é a chave de sua leitura da realidade: "que todo mundo fizesse uma voz única em coro, que fosse capaz de produzir um som eternamente audível, ressoando os lamentos e os direitos sonegados de todos". ${ }^{34}$

Evaristo constitui a ambiência de uma favela que é emaranhado de narrativas, relações, sentimentos, indagações, que convergem sobre a protagonista exigindo dela entendimento e sentido: "Fatos estavam acontecendo, mas só conseguia um melhor entendimento por meio das narrações que ouvia". ${ }^{35}$ MariaNova encarna nessa escuta hiperdimensionada das narrativas que circulam no território o procedimento que a própria Conceição Evaristo afirma estar na gênese de sua escrita, o acúmulo das palavras, sons, vozes ouvidas na infância e que são transformados em histórias para incomodar o sono injusto das elites:

Escrevo como homenagem póstuma à Vó Rita, que dormia embolada com ela, a ela que nunca consegui ver plenamente, aos bêbados, às putas, às crianças vadias que habitam os becos da

\footnotetext{
${ }^{23}$ Ibidem, p.196.

${ }^{24}$ HAESBAERT, op.cit., p. 313.

${ }^{25}$ Ibidem, p.315.

${ }^{26}$ EVARISTO, op. cit., p. 220.

${ }^{27}$ Ibidem, p. 120.

${ }^{28}$ Ibidem, p. 163.

${ }^{29}$ Ibidem, p.207.

${ }^{30}$ Ibidem, p. 115.

${ }^{31}$ Ibidem, p.243.

${ }^{32}$ Ibidem, p. 215.

${ }^{33}$ Ibidem, p.90.

${ }^{34}$ Ibidem, p. 230.

${ }^{35}$ Ibidem, p. 78.
} 
minha memória [...] Homens, mulheres, crianças que se amontoaram dentro de mim, como amontoados eram os barracos de minha favela. ${ }^{36}$

Vários pesquisadores que se debruçaram sobre a obra registraram essa pluralidade de vozes que aí se inscrevem: romance coletivo, na compreensão de Eduardo de Assis Duarte que redige a orelha do romance, justamente ilustrando aquilo que a partir de Zilá Bernd ${ }^{37}$ passa a ser um aspecto da compreensão da literatura afro-brasileira: a ampliação da voz individual em direção à coletividade.

Mas o sentido que se tece a partir dessas narrativas ouvidas não é outro que a incômoda relação passado-presente: "duas ideias, duas realidades, imagens coladas machucavam-lhe o peito. Senzalafavela". ${ }^{38}$ Eis a contração espaço-temporal que a protagonista passa a viver no decorrer das escutas e andanças pela favela e que será a chave de seu aprendizado e da vontade de escrever essa "história viva que nascia das pessoas, do hoje, do agora" 39 :

Pensou em Tio Totó. Isto era o que a professora chamava de homem livre? [...] Tinha que contar sobre uma senzala que, hoje, seus moradores não estavam libertos [...] olhou novamente a professora e a turma. Era uma história muito grande! Uma história viva que nascia das pessoas, do hoje, do agora. Era diferente de ler aquele texto. ${ }^{40}$

Uma outra história que "um dia, ela haveria de narrar, de fazer soar, de soltar as vozes, os murmúrios, os silêncios, o grito abafado que existia, o grito abafado de cada um e de todos. Maria-Nova um dia escreveria a fala de seu povo". ${ }^{41}$

\subsection{Texaco: o território como campo de batalha}

Em Texaco, Marie-Sophie Laborieux é quem narra as muitas histórias que ouviu de seu pai Esternome ao urbanista da prefeitura encarregado de tratar da demolição do bairro. Histórias que registra em cadernos arquivados junto à Biblioteca Schoelcher, cujas pequenas notas o romance apresenta aqui e ali, indicando o número do caderno, da página, do ano. Numa dessas notas, registra-se a voz viva de Esternome à filha Marie-Sophie:

Oh, Sophie, meu coração, você diz "a História”, mas isso não quer dizer nada, há tantas vidas e tantos destinos, tantas trilhas para fazer nosso único caminho. Você, você diz a História, eu, eu digo as histórias. Aquela que você acredita ser a raiz de nossa mandioca é apenas uma raiz entre um bocado de outras...

Caderno no. 6 de Marie-Sophie Laborieux

Página 18. 1965. Biblioteca Schoelcher. ${ }^{42}$

Aqui também há um desejo de reescrita da História pelas histórias contadas e recontadas de pai para filha, que nos levam ao espaço-tempo das fazendas de cana, onde os pais de seu pai viveram como escravos: o avô, deixado morrer numa masmorra por sua resistência à escravidão, a avó, que insiste em ter um filho em meio às palavras de ordem "nada de filhos da escravidão". Os relatos de Esternome vão, assim, das histórias de seus pais à sua história de escravo casualmente liberto por salvar a vida do senhor de escravos, que passa a deambular entre fazendas e cidades no período pré e pós-abolicionista atraído

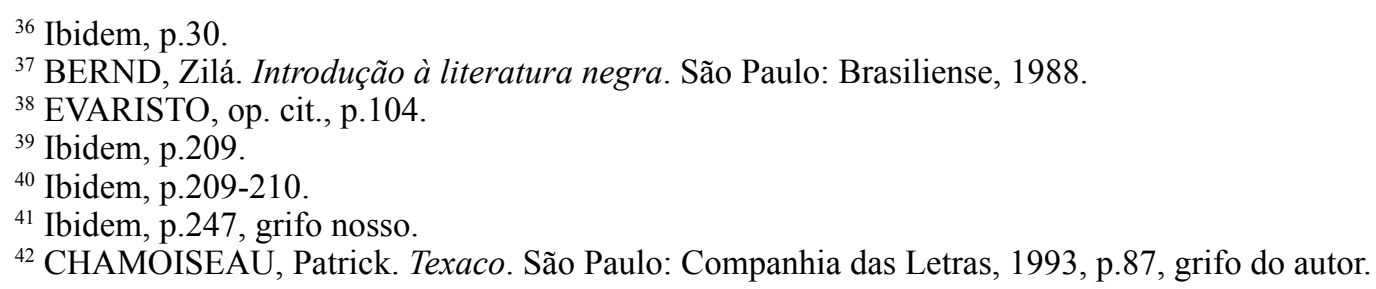


pelas cidades de Saint-Pierre e Fort-Royal, posteriormente chamada de Fort-de-France, fugindo dos campos e assumindo os trejeitos de "negro livre da Cidade". Difícil decisão para a população escrava, com a abolição e a substituição da ilusão da divisão das terras pela "cantiga do Trabalho", entre ficar no campo - onde "os negros teriam preferido [...] para existir. O campo para se alimentar. O campo para ser compreendido, o campo para morar"43 - e a cidade: "Cidade alta. Cidade maciça. Cidade portadora de uma memória da qual estavam excluídos"44; "cidade apinhada de negros errantes", ${ }^{45}$ cidade-enigma. Errando pelas cidades com seu pai, está Ninon e, depois de sua morte, Indomenée, ex-escrava de uma fazenda próxima a Fort-de-France, que será a mãe de Marie-Sophie.

Aos poucos, em novos "tempos de madeixa e caixote" que iniciam o século XX, essa oposição entre campo e cidade vai dar lugar a uma rica semântica que dividirá os dois espaços da cidade entre "centro histórico, ocidental" e "cinturões que sobrevivem da memória", entre centro e "bairro dos miseráveis", entre "oceano" e "havre", entre "cidade" e a pergunta "e isso é uma cidade?", entre cidade e "terra instável" que luta contra a água, entre homens, que têm por única tarefa construir o próprio barraco, e mulheres, que precisam encontrar comida "sem ter uma roça", devendo "plantar em si mesmas um pequeno roçado de astúcias". ${ }^{46}$ É o tempo de Marie-Sophie criança, que encontrará mais tarde, com a morte dos pais e a perda do barraco, seus próprios meios de sobrevivência na cidade, vagando de "casa em casa, de patroa em patroa"47 até a primeira fundação de Texaco, em "tempos de fibrocimento", seguida de várias expulsões, quando a cidade, mesmo com uma prefeitura de esquerda, "não se oferecia fácil como um prato de mingau". ${ }^{48}$ Foi preciso que "os comunistas compreendessem" esse "proletariado sem fábricas, sem oficinas, e sem trabalho, e sem patrões, perdido nos biscates, mergulhado na sobrevivência [...] Que gente é essa ?. $^{49}$

Assim, pelos "jardins da memória" cultivados por pai e filha, ${ }^{50}$ temos acesso ao mundo cindido da escravidão entre campo e cidade, entre negros do campo e da cidade, entre sujeitos em escalas de cor - "Meu Esternome aprendeu a designar cada pessoa de acordo com seu grau de brancura ou o azar de sua negrura" 51 -, entre liberdade e trabalho, e, com o tempo, entre os "rostos da cidade" que o urbanista aprende a ler a partir dos relatos de Marie-Sophie:

Ela me ensinou a reler os dois espaços de nossa vida crioula: o centro histórico, que vivia das novas exigências do consumo; os cinturões de ocupação popular, ricos em vestígios de nossas histórias. Entre esses locais, a palpitação humana que circula. No centro, destruímos a lembrança, inspirando-nos nas cidades ocidentais e à guisa de renovação. Aqui, no cinturão, eles sobrevivem da memória. No centro, perdemo-nos no moderno do mundo; aqui têm raízes muito antigas, não profundas e rígidas, mas difusas, profusas, espalhadas no tempo com a leveza que a palavra confere. Esses pólos, unidos ao sabor das forças sociais, estruturam com seus conflitos os rostos da cidade

Nota do urbanista ao Marcador de Palavras

Pasta no. 3, Folha XVI.

1987. Biblioteca Schoelcher ${ }^{52}$

\footnotetext{
${ }^{43}$ CHAMOISEAU, op.cit., p. 81 .

${ }^{44}$ Ibidem, p.80.

${ }^{45}$ Ibidem, p. 107.

${ }^{46}$ Ibidem, p.156-7.

${ }^{47}$ Ibidem, p. 202.

${ }^{48}$ Ibidem, p. 274.

${ }^{49}$ Ibidem, p.279, grifo do autor.

${ }^{50}$ Ibidem, p. 65.

${ }^{51}$ Ibidem, p.71.

${ }^{52}$ Ibidem, p. 155.
} 
O romance dilata ao infinito as dobras e o espaço narrativo de uma possível remoção, entre a "Anunciação" "53, que traz a visita do urbanista ao bairro a "questionar a utilidade de nossa insalubre existência" (1993, p. 21), ${ }^{54}$ e a "Ressurreição", que fornece uma imagem cristalina do bairro sendo consolidado com a interrupção do processo de despejo. Entre essas duas pontas, as muitas narrativas que reconta Marie-Sophie Laborieux, de seu pai e avô e de si própria preenchem, com linguagem desconstrutora, essas grandes temporalidades rasuradas que vão de "tempos de palha" do século XIX aos "tempos de fibrocimento" e "tempos de concreto" do século XX e da fundação de Texaco. Ao contrário de Becos da Memória, a existência dessa líder comunitária, que fundou e refundou o bairro por tantas vezes, e a sua longa narrativa ao urbanista encarregado da demolição, fazem com que Texaco seja "reabilitado": "[Texaco] minha obra, nosso bairro, nosso campo de batalha e de resistência. Ali levávamos adiante uma luta pela Cidade, começada já havia mais de um século". ${ }^{55}$

\section{3-Das narrativas orais à construção da escrita afrodescendente}

A rica construção de imagens, em Texaco e Becos da memória, da saga dessas famílias em busca de um território fala desse processo difícil de territorialização da diáspora negra nas Américas que, desde a perda do território africano, deambula pelas margens de nossas sociedades, que lhes negou reiteradamente o direito à terra e ao campo e lhes nega o direito à parte estável e organizada das cidades, empurrando-os para os morros, onde outras forças de desterritorialização os atingem, das águas, das remoções; ou, como no final de Texaco, até que a cidade se reconcilie com a cidade e reabilite esses espaços.

Nesse percurso, os dois romances nos fazem pensar na memória e na preservação desses vestígios de homens e mulheres pelas narrativas orais como estruturante das experiências negras no processo de ocidentalização forçada da diáspora, estando a sobrevivência e o entendimento do mundo atrelados à escuta - e, para poucos, à escrita - dessas outras histórias que a história oficial silenciou. Um pouco à maneira de Hall, ${ }^{56}$ retomando Frantz Fanon, a memória cumpre aqui o papel de reescrever um passado que foi esvaziado, distorcido, destruído, o que é parte do processo de colonização (e escravidão). Ao se re-contar o passado, permite-se revisar os modos como o discurso dominante posicionou não só objetivamente, mas subjetivamente o sujeito negro em relação a seu passado: "a expropriação íntima da identidade cultural". ${ }^{57}$

As duas personagens, através das narrativas ouvidas e recontadas, são capazes de desler a história e explicitar uma série de relações não ditas ou interditas entre tempos e espaços descontínuos: ao recontar essas histórias, sobretudo ao escrevê-las como querem Maria-Nova e Marie-Sophie, abre-se o espaço literário para a própria dramatização da complexa conquista de espaços da escrita afrodescendente e de sua tarefa: "porque a memória histórica foi rasurada com demasiada frequência, o escritor antilhano

\footnotetext{
${ }^{53}$ Em Texaco, esse substrato metafórico associado ao texto bíblico e seus significados é ativado explicitamente por Chamoiseau, pelas escolhas lexicais dos títulos que dividem as partes: "Anunciação", "O sermão de Marie-Sophie Laborieux", "Tábua primeira", "Tábua segunda", "Ressurreição" etc. Stuart Hall, sobre a produção cultural no Caribe e nos Estados Unidos, mostra como um substrato metafórico próprio à experiência do sofrimento e exílio, do livramento e da redenção, que está nas narrativas judaicas da Bíblia, serve, nas diásporas negras, para tratar para tratar da fuga da escravidão, do cativeiro, em um jogo de metáforas paralelas, constituindo um duplo texto que interessou aos estudos culturais. Hall, Da diáspora , op. cit.

${ }^{54}$ CHAMOISEAU, op.cit., p.21.

${ }^{55}$ Ibidem, p.33.

${ }^{56}$ HALL, "Identidade Cultural e Diáspora", op.cit., p.69.

${ }^{57}$ Ibidem, p.70.
} 
deve 'vascular' essa memória a partir de vestígios por vezes latentes que ele detectou no real" ${ }^{58}$ Não é outra a tarefa do Marcador de Palavras em Texaco, aquele que faz falar a palavra, a memória, que assim reata "o fio da vida" 59 entre tantas vidas "amontoadas", como escreve Evaristo.

Imagens dessa memória coletiva nos são dadas pelas metáforas rizomáticas de Chamoiseau: "uma raiz entre um bocado de outras..."; "aqui têm raízes muito antigas, não profundas e rígidas, mas difusas, profusas, espalhadas no tempo com a leveza que a palavra confere". Substrato que ressoa também em Becos da Memória e que nos permite ressignificar a semântica da raiz e do enraizamento, pensada comumente como imagem de uma vida que se quer fixa e individualizada. Aqui a construção dessas memórias da diáspora é desejo de enraizamento de vidas em outras vidas, enraizamento difuso, profuso, espalhado entre tempos rasurados e espaços exíguos.

Esses dois romances, escritos no final do século XX, constituem cartografias atualizadas de processos que não se extinguiram com o final de século e ganham hoje novos discursos e novos silêncios ${ }^{60}$. São prova da abolição inconclusa de nossas sociedades e de quanto ainda precisamos caminhar em termos de reabilitação de nossa vida social, se quisermos superar as heranças da escravidão que insistem em nosso presente. A memória que esses romances constitui nos importa: "a memória de todo massacre ou de todo genocídio, ela importa ao equilíbrio do mundo [...] a memória recuperada é antes de tudo uma ferramenta de solidariedade entre povos". ${ }^{61}$ Esses escritores ajudam-nos, assim, a juntar os fios ainda soltos dessa memória coletiva da escravidão transatlântica e de sua diáspora, que se fez e se faz silenciar por vários meios, inclusive pela não criação pela França do prometido "Centro nacional pela memória das escravaturas e duas abolições", idealizado por Glissant para ser exatamente o espaço de porosidade e transversalidade entre povos na pesquisa da escravidão e de suas heranças.

Se podemos convocar com alguma propriedade o conceito de estrutura de sentimento de Raymond Williams para abarcar essas escritas diaspóricas que se fazem à distância, entre línguas, países e espaços diversos, é exatamente nesse sentido de escrita de histórias transversais que ligam os muitos fios de nossa memória coletiva. A literatura faz, assim, esse trabalho transversal de tornar menos "opacas", "indistintas" e "impermeáveis" as várias escravidões do povo negro, fazendo "o movimento contrário do que se passa nas histórias das escravaturas", ${ }^{62}$ tornando-se um vetor da memória coletiva e da solidariedade entre os povos que viveram a escravidão transatlântica.

Recebido em: 19/10/2015

Aprovado em: 15/12/2015

\footnotetext{
${ }^{58}$ GLISSANT apud CHAMOISEAU, op. cit., p. 341.

${ }^{59}$ CHAMOISEAU, op. cit., p.262.

${ }^{60}$ No Brasil, uma nova leva de remoções para a "revitalização" das grandes cidades em um processo de "despossessão dos ativos territoriais dos mais pobres, que é parte da acumulação do capital em novas bases" (ROLNIK, Raquel. "Prefácio". In: FAULHABER, L.; AZEVEDO, L. SMH 2016. Remoções no Rio de Janeiro. Rio de Janeiro: Mórula, 2015, p.12) coloca em situação de remoção não menos que 170 mil pessoas. Remoções que têm ocorrido, em geral, sob a chancela dos governos e às custas de violações de direitos, desinformação, ameaças e segregação dos pobres nas periferias distantes. Raquel Rolnik, que foi relatora da ONU para o direito à moradia adequada entre 2008 e 2014, enfatiza o quanto a "opacidade" e a falta de registros e de respostas imperam ao se buscar informações sobre esses processos junto aos governos e instituições responsáveis.

${ }^{61}$ GLISSANT, Mémoires des esclavages, op. cit., p.124.

${ }^{62}$ Ibidem, p.147.
} 